\title{
The value chain and activities of polyethylene terephthalate plastics in the South African waste economy
}

Local Economy

2020, Vol. 35(5) 523-535

(C) The Author(s) 2020

Article reuse guidelines: sagepub.com/journals-permissions DOI: I0.II77/026909422093 I697 journals.sagepub.com/home/lec

(\$)AGE

\section{Marlin Hoffman (D) and Catherina Schenck}

University of the Western Cape, South Africa

\begin{abstract}
Introduction: Value chains in their entirety, within the South African context, have not been the focus of much research thus far. A plethora of research has been done on the various actors within the value chain, but the rest of the value chain has not been identified and depicted. Failing to understand and describe the entire value chain of polyethylene terephthalate plastics has led to many unanswered questions and misunderstood impacts on the plastics waste economy.

Purpose: The purpose of the study was to document and depict the value chain and its activities within the polyethylene terephthalate waste economy in South Africa, which, according to the available literature, has not been done before. The documentation of the value chain and its activities will assist in identifying the possibilities of job creation within the waste economy, which could impact the diversion of waste from the landfill.

Method: A qualitative research approach with an exploratory research design was followed, and the data collection was done by means of a workshop. The participants in the workshop included captains of industry, entrepreneurs, academics, government, environmental groups and environmental non-governmental organizations. The workshop was recorded audio-visually, and concepts and discussions were documented for this purpose. All information was transcribed and documented in a final document.

Results: The value chain and its activities were documented.

Conclusion: The information collected is a starting point for more research within the waste economy, as the process will be followed with other waste streams. Job creation gaps have been identified and further research has started creating a better understanding of the value chain, which will influence policy.
\end{abstract}

\section{Keywords}

job creation, unemployment, value chain, value chain activities

Corresponding author:

Marlin Hoffman, University of the Western Cape, Robert Sobukwe Road, Bellville, Western Cape 7535, South Africa. Email: mjhoffman@uwc.ac.za 


\section{Introduction}

Prior to the 1960s waste was linearly managed through an approach of take, make, use, dispose of (usually at a landfill) or pollution (Andrews, 2015). Recycling is an integral component of sustainable waste management, which finds itself in the formal and informal sector valorisation activity (Wilson et al., 2013), and it relies on source segregation, collection, sorting and trading into the local, national and international markets (Scheinberg, 2012). Scheinberg $(2011,2012)$ mentioned that waste valorisation is broader than the concept of recycling as it takes into account the commercialisation of recycled materials. Velis et al. (2012) further noted that it is essential to develop the value chain, which will fully integrate the informal sector into the waste management system in developing countries. Scheinberg and Simpson (2015) used the term 'value chain recycling' to describe the private sector recycling activities which depend on revenues solely from selling recovered materials. Jaligot et al. (2016) stated that the position of the informal sector recyclers is often at the beginning of the value chain, which means collecting dirty material for sale at a low price and to which others add value. Value chain analysis also allows for an analysis of how to improve the livelihoods of those upstream, towards the beginning of the chain, for example by modifying particular steps within the chain and the interaction between them (Humphrey and Navas-Aleman, 2010).

Sections of the waste value chain have been researched within the recycling sector, and the informal sectors have primarily been the focus in many developing countries (e.g. Jaligot et al., 2016; Milios et al., 2018; Steuer et al., 2017; Zamora, 2016). The aforementioned research was conducted for various reasons, including understanding the components of a value chain in a particular country or region, to understand the impact made by the informal players and the possibility of opportunities or threats within the value chain. In the case of this study, the researchers set out to depict the value chain of polyethylene terephthalate (PET) plastics valorisation within South Africa in order to develop a framework within which the actors can be identified and plotted. The value chain for recycling in South Africa has not been explored before. Once the value chain framework has been determined and documented further, more focused studies will be conducted to look at each component of the value chain. The lessons learnt from this research will assist in the documentation and mapping of value chains relating to the various waste streams. There is a need to understand what value is added throughout the value chain, as well as the actors within the value chain responsible for adding the value. Therefore, this study is understood to be the forerunner of said studies which will focus on researching components of the value chain.

As far as the researchers are aware, no study has yet been conducted on the value chain of plastics (PET) in South Africa. As mentioned earlier, understanding the value chain is imperative to understanding the dynamics and operations within the plastics waste economy, as there is currently no clear picture thereof. The study set out to clarify and depict the value chain of plastics waste within the South African context.

\section{The South African context}

South Africa had to overcome many obstacles, including those of its past, to hold its first democratic elections in 1994, which marked the dawn of a new era where all the country's citizens are free and equal politically, economically and socially, which was a freedom never experienced before. With the intervention of affirmative action and black economic empowerment, there 
was a sizeable progression of black South Africans into the middle class (Mattes, 2014). This newfound economic freedom allowed for the migration of many people from the rural areas to the city centres; however, the infrastructure could not accommodate this influx. Added to this was the increase in population growth that impacted the country economically and environmentally and subsequently resulted in a spike in general waste disposal. Statistics South Africa (Stats SA, 2018) reported in its mid-year population estimates that over the past 12 years 140,000 citizens had migrated from the Eastern Cape to the Western Cape, resulting in the Western Cape now having more citizens than the Eastern Cape which was not previously the case. Similarly, it is estimated that more than 10 million people from other countries in Africa have migrated to South Africa due to economic and political instability and the rapidly growing informal settlements (Taylor and Triegaardt, 2018). This has placed more pressure on the already struggling-to-cope South African infrastructure, and issues with service delivery are contributing to the waste disposal problems being experienced.

At the same time unemployment has become and remains one of the major important economic issues that has found political and socio-economic prominence in South Africa since 1994 (Du Toit et al., 2018). Due to the apartheid education system of the past, many black South Africans who did not receive equal education were unemployed and could not find jobs in the formal market (Jansen, 2002) in order to sustain their families, even after migrating to the cities to seek employment. The unemployment rate in South Africa has always been a problem and it has escalated to $29.1 \%$ as reported for the last quarter of 2019 (Stats SA, 2019).

The government has unsuccessfully implemented initiatives such as the Reconstruction and Development Programme (RSA, 1994) and the Growth, Employment and Redistribution Strategy since 1994 (Taylor and Triegaardt, 2018). However, there seems to be no remedy for the unemployment problem which continues to be experienced. With the growth of the middle class in South Africa, a subsequent environmental impact was experienced. Due to increased disposable income, general waste increased to 108 million tonnes in 2011 (DEA, 2012). South Africa is running out of landfill space, since $90 \%$ of all generated waste ends up on the landfill, as other possible means of disposal are not fully utilised. This means that only $10 \%$ of waste generated is diverted from the landfill space through the waste economy value chain. Godfrey and Oelofse (2017) illustrated the importance of the role of the waste picker, as the waste picker diverts $90 \%$ of the $10 \%$ waste diverted from landfill, to be the link between the service chain and the value chain. Godfrey and Oelofse (2017) further illustrated the service chain as comprising the municipal activities and the value chain comprising the formal and informal business sectors within the waste economy.

According to GreenCape (2017) the government has recognised the environmental problem that is currently being faced, coupled with the fact of the high unemployment rate; therefore, one of the obvious solution would be to also look at the waste economy for employment opportunities. To take advantage of these employment opportunities, entrepreneurs need to enter the value chain of the waste economy.

South Africa has been struggling with a high unemployment rate ever since the establishment of a democratic government in 1994. The unemployment rate in 1994 was 20\% (Stats SA, 1998). The current unemployment rate is $29 \%$ out of a working population of 22.5 million citizens. There are 16.3 million people employed 
within the formal, informal, agricultural and private household sectors. There are 6.2 million citizens unemployed, with 15.8 million who are economically inactive (Stats SA, 2019).

Godfrey and Oelofse (2017) noted that the government estimated between 60,000 and 90,000 informal waste pickers in South Africa; however, they estimated that there may actually be 215,000 waste pickers. This must be seen in contrast to the 30,000 municipal workers in the waste service chain. The reason for waste pickers' existence is based on and due to rising unemployment and urbanisation. The waste pickers provide waste, which is ultimately used by recyclers, to various actors within the value chain (Godfrey and Oelofse, 2017).

The unemployment problem was addressed in the National Development Plan (NDP) 2030 (RSA, 2013) that estimated that 11 million jobs must be created by the year 2030 for the country to be economically sustainable. To achieve this number, there have been many government initiatives focusing on job creation. The NDP 2030 (RSA, 2013) has identified and tasked entrepreneurship and small business development as the vehicles to alleviate unemployment and impact economic growth in the future of the country. As previously mentioned, the growth of the middle class in South Africa has impacted South Africa environmentally due to increased disposable income, which increased general waste to 108 million tonnes as at 2011 (DEA, 2012). The Department of Environmental Affairs has used these data and extrapolated it to estimate waste produced in 2016 to have increased to 111 million tonnes and thereby the waste economy could contribute R24.3 billion to the GDP of the country (DEA, 2017). Greencape (2017), on the other hand, stated that the current market size of the waste economy was R960 million with a potential to grow to R3.6 billion, which equates to a job creation of 7860 jobs. The potential of the waste economy is sizeable in relation to job creation and absorbing labour into the sector; however, the exploitation and exclusion of informal labour, as mentioned earlier, is a concern. Therefore, work focusing on the protection of waste pickers is currently underway, as they are the most vulnerable persons in the waste economy.

The legislative process within waste management started with the promulgation of the Environmental Conservation Act (Act 73 of 1989) (RSA, 1989) which was amended and set out requirements for the management of waste it was also the first legal definition of waste. The majority of the focus was on permitting, control and management of waste disposal sites with the intention being to reduce the environmental impacts as a result of poorly operated landfills many of which were just controlled and uncontrolled dumpsites (Godfrey and Oelofse, 2017). The act also gives the Minister of the Department of Environmental Affairs and Tourism (DEAT) the authority to make regulations relating to reduction, reuse and recovery of waste although this was never used (Godfrey and Oelofse, 2017). With the promulgation of the National Environmental Management: Waste Act 2008 (Act 59 of 2008) (RSA, 2008) a legislative requirement was the National Waste Management Strategy which gave rise to many regulations between 2008 and 2017 which included the National Environmental Management: Waste Amendment Act (Act 26 of 2014) (RSA, 2014).

The aim of the study was to identify, document and depict the waste value chain. The researchers used PET plastics as a case study, including the path these plastics follow through the economy, from being purchased by the consumer to being recycled and reused. The study yielded more than what was aimed at, as it also assisted in identifying the potential 
employment opportunities within the plastics (PET) waste value chain.

\section{The value chain}

The value chain, as a concept, was first introduced by Porter (1985) who described the full range of activities required to take a product or service from ideation through the various steps to distribution to endusers, and finally disposal after usage. Stabell and Fjeldstad (1998) confirmed that Porter's (1985) value chain framework can be used for the analysis and representation of firm-level value chain logic. Hellin and Meijer (2006) postulated that a product moves from one actor to another and that it is assumed to gain value during the process. Thus, the value chain can be used to disaggregate an industry into major activities, thereby identifying sources for competitive advantage (Brown, 1997). The realised benefits of the concept have resulted in a growth in the literature within the fields of management and economics (AbecassisMoedas, 2006).

Abecassis-Moedas (2006) argued that one way to categorise or classify a value chain is in terms of who drives the chain - whether the chain is buyer-driven or the chain is producer-driven. The characteristics of buyer-driven chains are that they are labour-intensive consumer goods industries, where large retailers and trading companies play a central role in the formulation of production networks, usually in developing countries. Producer-driven chains, on the other hand, are characterised by capitalintensive, technology-oriented industries dominated by large transnational corporations which play a key role in managing production networks (Abecassis-Moedas, 2006). Zamora (2016) pointed out that irrespective of who drives the chain, value-adding should be reflected through the natural sequence of operations from one stage to another or from one activity to another. Chivaka (2007) mentioned that value-adding implies both value created and value captured since every strategically significant activity performed requires an investment in resources, and therefore each link in the chain is expected to add value. Jaligot et al. (2016) supported this understanding by adding that each step and link in the value chain has a source of input - a process of value-adding by selling the material to the next link in the value chain.

According to Kaplinsky and Morris (2003) value chain analysis addresses the weakness of traditional analysis as it tends to be static and limited in identifying factors of success. Value chain analysis focuses on the dynamics of multifaceted linkages within a network where both value creation and value capture occur in a value system that includes each actor throughout the system (Zott et al., 2011). Therefore, according to Zamora (2016) value chain analysis requires the 'mapping of the market' to track and analyse the contribution of the different chain actors and the relationships among them. To understand the interactions between the actors and the activities that they perform, it is imperative to understand the factors that influence how well or not the chain works. This form of analysis is important to a developing country, like South Africa, to appreciate the significance of assessing the performance of the waste management sector from a value chain perspective.

\section{Methodology}

To be able to identify and map the waste, in particular the PET value chain, the research methodology followed was a two-step approach. First, a literature study was conducted on the activities and actors in the waste value chain, and second a workshop was facilitated. 


\section{Step I: Literature study}

A literature review was conducted on international research that had been done to ensure that the work and research conducted was based on a foundation that laid in peer-reviewed literature focusing on recommendations and existing frameworks from other developing countries (Velis et al., 2012). It was decided that the guidance provided from peer-reviewed literature would be followed in identifying and documenting the PET plastics value chain. It appears that no published work has been done, as far as the researchers are aware, on the documentation of the plastics waste (PET) value chain in South Africa other than actors within the value chain such as the waste pickers and buyback centres, as mentioned earlier. Porter's (1985) value chain framework was used as a starting point in documenting the value chain for PET plastics.

\section{Step 2: Facilitation of a workshop}

To explore the plastics waste value chain within the South African context, a qualitative research approach with an exploratory research design was followed. It was decided to collect data by means of a workshop. Experts and stakeholders in the waste sector such as academics, environmental agencies, government, governmental agencies, the waste industry dealing with the plastics waste management industry and those who own businesses within the industry were invited to the workshop to assist in identifying, describing and mapping the waste value chain with PET as an example. The reason for using PET is that PET in South Africa is currently the product which has the highest recycling rate and a well-developed value chain. According to PETCO (2020) 98,649 tonnes of PET bottles (6\% up from 2017 year on year) were recovered and recycled during 2018 in South Africa.

A workshop is defined by the Collins Online Dictionary (2020) as a period of discussion or practical work on a particular subject in which a group of people share their knowledge and experience. Ahmed and Ashraf (2018) argued that a workshop can be considered as a qualitative research data collection opportunity approach, as it allows for the use of multiple modes of data collection, and at the same time allows for triangulation, which is another means of establishing the credibility and trustworthiness of the data and the study. Through the workshop process, researchers can illicit rich information from participants who are selected to attend (Ahmed and Ashraf, 2018). Ørngreen and Levinsen (2017) postulated that workshops should be conducted with people who have experience in the domain. Active and genuine participation should be promoted, which will result in reliable and valid data about the domain in question. Ørngreen and Levinsen (2017) in particular see workshops as suitable data collection opportunities in studies that are exploratory, emerging and unpredictable, allowing for group discussions, brainstorming and diligent observation (Lincoln and Guba, 1985), which gives the researcher time to scrutinise the issues and concerns, and adds to the establishment of the study's credibility (Lincoln and Guba, 1985; Pandey and Patnaik, 2003) and rigour (Houghton et al., 2013; Wallendorf and Belk, 1989). The researcher, as an active participant in the workshop becomes a research instrument that creates the space for interaction of the respondents so they feel comfortable in sharing their experience and knowledge with the facilitator (Owen, 2006).

Workshops as data collection opportunities foster engagement among the participants and between the participants and the facilitator, which is a crucial element 
for success (Ahmed and Ashraf, 2018; Lain, 2017). Collaborative discussions and constructive feedback take place among the participants and between the participants and the facilitator of the workshop (Spagnoletti et al., 2013). Engagement is considered one of the primary ways of establishing the credibility of the results of a qualitative study (Erlandson et al., 1993; Pandey and Patnaik, 2003; Shenton, 2004), and building and maintaining the trust between the researcher and participants (Merriam, 1998). Ahmed and Ashraf (2018) posited that the intense engagement between the workshop facilitator and the participants allows researchers to obtain thick and rich data in the course of interaction and that the facilitator becomes the medium through which data are collected or, as Spradley (1979) noted, the research instrument of the study. According to Cornwall and Jewkes (1995) there are four types of participation that could take place within a workshop setting; however, only two were identified for the purpose of this study. The two participation types are collaborative and collegiate. Collaborative is where the researcher and participants work together, but with the researcher in control (Cornwall and Jewkes, 1995). Collegiate refers to a situation where the researcher and participants contribute in a mutual process controlled by the participants (Cornwall and Jewkes, 1995).

The workshop started with a presentation by the first author on the current literature, which included the theory of value chains and instances where value chain analysis was conducted within the waste management industry. Thereafter, questions were posed which elicited responses from the group as to the various phases or paths that PET waste followed through, by activity, within the value chain.

The workshop was documented in two ways, namely notes that were taken during the workshop by appointed scribes and an audio-visual recording of the workshop. The audio-visual recording was later transcribed and the two sources of data collected, scribed and transcribed were collated to get to the final result of the workshop. Permission to conduct research on the waste value chain was granted by the Senate Research Committee of the University of the Western Cape. The activities within the value chain were documented, irrespective of whether they occurred within the formal or informal sector within plastic waste. As all the players within the value chain were represented to some or other degree, it gave the work group a clear picture of the value chain within plastics waste. The next section will discuss the results of the workshop as agreed by the participants.

\section{Results}

After the presentation of the literature to the group by the first author and facilitator, the group commenced by describing the value chain by identifying the actors in the PET value chain. It was then realised that some actors are role-players in more than one activity. Consensus was then reached to describe the PET value chain according to the activities in order to provide a framework to plot the actors and result in a clearer process.

Figure 1 depicts the results or outcomes of the workshop where each activity and the possible role-players within each activity of the plastics waste value chain were documented to give a clear understanding of what activities take place within the value chain. Seven activities were identified within the PET value chain by the participants in the workshop.

\section{Consumer activity}

We started at the point where the consumer buys a beverage (for example a 2 litre PET bottle) from a retailer and the collection 


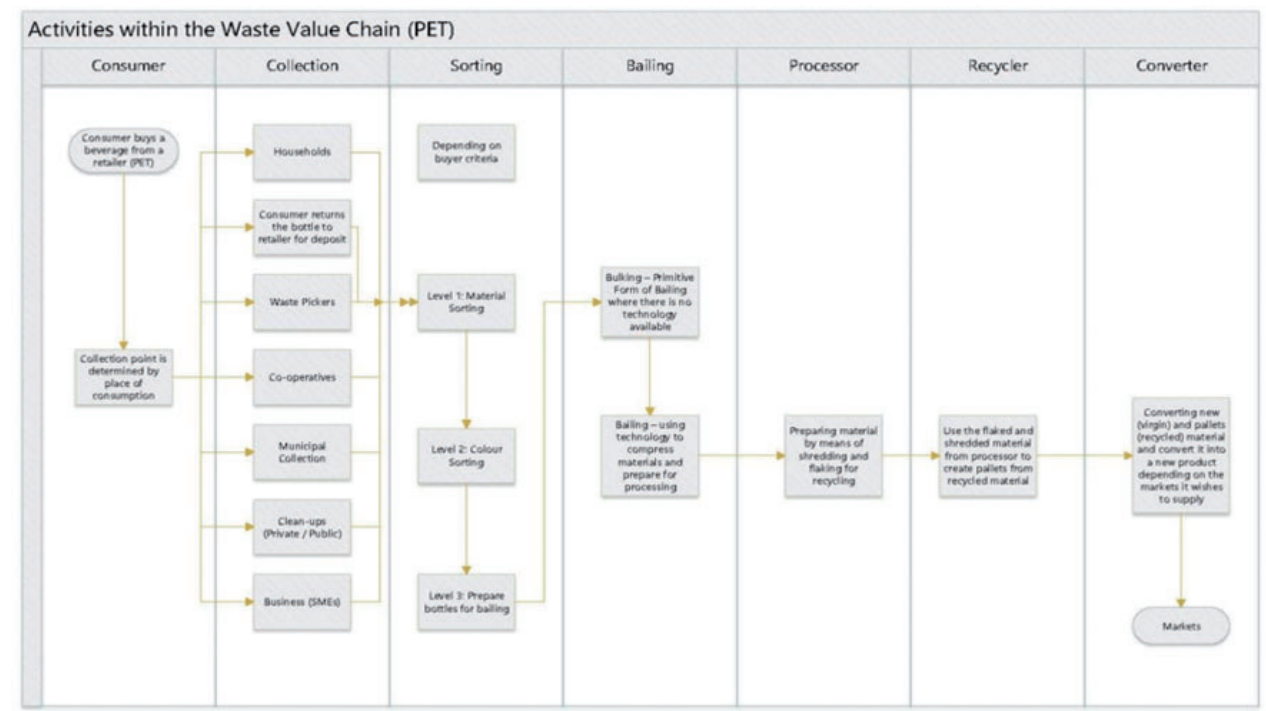

Figure I. Activities within the value chain (PET). PET: polyethylene terephthalate; SME: small and medium enterprises.

point of the PET is determined by the place of consumption of the beverage.

\section{Collection activity}

The collection activity can be done by various actors depending on the point of consumption and/or disposal. Waste can be collected via the service waste chain or the waste value chain.

An objective of the South African government, pertaining to waste management, is to ensure that all households in the jurisdiction of a municipality are provided with equitable waste collection services. However, it is recognised that this is not always possible on a regular basis due to distance, which results in costs (DEA, 2018). Similarly, South Africa has managed to formally collect $59 \%$ of the waste from households (Stats SA, 2016).

Private service providers within waste management are contracted by municipalities to provide waste collection services for household, commercial and industrial waste within the municipal jurisdiction (GreenCape, 2019).
In the waste value chain households, informal waste pickers, bakkie and horse-cart collectors and co-operatives, formal municipal collection, clean-ups (public private) and businesses (SMEs delivering the service) were identified as the various points of collection. Informal waste pickers, as mentioned earlier, are estimated to number 215,000 and collect waste from two sources, namely kerbside or at landfills (Godfrey and Oelofse, 2017). Waste pickers are the main collectors of recyclables in South Africa and are the starting point of the waste diversion process from the landfill. According to Plastics SA (2017), 80-90\% of packaging waste is recovered by a large and active informal sector. Co-operatives have been promoted by various South African government initiatives, as these are seen as a promising business model to stimulate job creation and enterprise development, coupled with enabling legislation, to strengthen the local recycling economy (Godfrey et al., 2017). Godfrey et al. (2017) found, however, that co-operatives have thus far not been an effective business model in 
South Africa for various reasons, such as being top-down driven from government, along with ineffective training support and mentoring.

\section{Sorting activity}

The sorting activity is dependent on the buying criteria of the recyclers and subsequently the buyback centres. The buying criteria of the recyclers and buyback centres would range from how clean the PET plastics are to the various colours of the plastics. The waste picker would be paid more for clear plastics than for coloured plastics. The buying criteria were categorised into three levels:

- Level one is the sorting of materials;

- Level two is the sorting of materials into various colours; and

- Level three is the preparation of bottles for baling.

In their article about buyback centres, Viljoen et al. (2019) briefly discussed the operational activities of a buyback centre, which are value-adding activities, namely the proper sorting, cleaning and baling of materials. The importance of sorting and baling is that these activities will affect the price of the PET on its way to being recycled.

\section{Baling activity}

The baling activity has two components. The first component is bulking, which is a 'primitive' form of baling where there is no technology. Bulking is done when the waste picker prepares the PET plastic bottles by pressing them flat and removing the caps. They are then bound together depending on the requirements of the buyer. Baling is the other component, which uses technology to compress materials and prepare them for processing by means of a baling machine. The value added by baling is that the plastics are compressed into a smaller size which means that less space is being taken up for storage, and, because it is compacted, it weighs more. It also makes for easier transportation of the plastics and reduces the storage costs of the plastics.

\section{Processor activity}

The processor activity adds value by preparing the material by means of shredding and flaking for recycling. According to Grigore (2017) mechanical recycling does not involve the changing of the polymer during the process; however, it is a method whereby plastic waste is formed by the cutting, shredding or washing of granules, flakes or pellets of desired quality for manufacturing for the recycling process. The processing activity is housed either with an independent processor who sells the end product to a recycler, or it is done by the recyclers themselves.

\section{Recycler activity}

The recycler activity uses the flaked and shredded material from the processor to create pellets from recycled material. The recycler activity is, in many cases, found in the formal sector and is done by companies that are the main suppliers of the recycled materials to companies that convert the recycled materials into new products.

\section{Converter activity}

The converter activity converts new (virgin) and pellet (recycled) material into new products depending on the market it wishes to supply. The recycled material can be blended with virgin material to obtain a superior product or results, and after the plastic is sorted, cleaned and dried it can be directly converted into end 
products, thus dramatically reducing the quantity of the plastics waste (Grigore, 2017).

Figure 1 graphically shows the activities within the value chain of PET plastics through the various activities from the starting point where the plastics are bought by the consumer at various retail outlets and other sources. The point of consumption and disposal of the PET plastic container will determine the point of collection. Seven points of collection have been identified in this process, ranging from households to business sites. The sorting activity comprises three activities that have been identified, namely materials sorting, colour sorting and preparation for baling of the PET plastics. In the baling activity two activities were identified, namely bulking, which is a primitive form of baling that does not require technology, and mechanised baling which requires technology. The processing activity involves shredding and flaking of the materials for recycling purposes, which will be sold to the recycler who will process it into a pellet form. The converting activity uses the recycled materials and virgin product and converts these into new products that enter the market and are sold to the consumer, which will start the entire process again. The depiction of the activities that were identified in Figure 1 also represents the circular economy within PET plastics.

\section{Discussion and conclusion}

The activities within the PET plastics value chain gave the researchers in this study a clear indication of the actors or roleplayers within the value chain and where they contribute to the value-adding activities. The collection activity where the waste pickers operate, be it on landfills or on the street, through to the baling activity within the informal buyback centres, is within the informal sector of the value chain. Much research has been conducted on the actors within the value chain that are made up of the informal actors within the waste economy, which include the collection activities through to the baling activities within the informal buyback centres (e.g. Godfrey et al., 2017; Hellin and Meijer, 2006; Jaligot et al., 2016; Scheinberg, 2012; Steuer et al., 2017; Velis et al., 2012; Viljoen et al., 2019). The value chain also has formal buyback centres (Viljoen et al., 2019), which have the same activities as the informal buyback centres, and which are included in the category with other formal sector actors such as processors, recyclers and converters.

At the end of the workshop process it was realised that Zamora (2016) was correct in pointing out that irrespective of who drives the chain, value-adding should be reflected through the natural sequence of operations from one stage/activity to another. It is also clear that in practice many of the activities could be happening under 'one roof' from a business perspective, for example collecting, sorting and baling could take place within one SME. Understanding the value chain and the value added throughout the chain is important for future research within the plastics waste (PET) value chain. The importance of this research is highlighted further in the fact that there has been no previous research that investigated the relationship among the various activities within the value chain. Much of the research has been conducted on the informal sector which includes waste pickers and buyback centres. Another actor within the value chain has been identified and is currently being investigated, namely the 'bakkie brigade'.

Future research will be conducted on the formal sector of the PET plastics value chain in order to understand the impact of the actors on the entire value chain, now that the value chain has been depicted. Adding value at each stage is vital to the 
survival of both informal and formal businesses, as adding value comes at a price. Future research should also include understanding relevant business models and the opportunities and barriers to entry for small businesses and job creation in the value chain. This is especially important in the South African context due to the country's high employment rate and economic growth.

\section{Declaration of Conflicting Interests}

The author(s) declared no potential conflicts of interest with respect to the research, authorship, and/or publication of this article.

\section{Funding}

The author(s) disclosed receipt of the following financial support for the research, authorship, and/or publication of this article: The authors acknowledge the funding support for the preparation of this paper from the South African Department of Science and Innovation (DSI), through the Waste RDI Roadmap, managed by the Council for Scientific and Industrial Research (CSIR) and the National Research Foundation (SA).

\section{ORCID iD}

Marlin Hoffman (D) https://orcid.org/0000-00027926-9146

\section{References}

Abecassis-Moedas C (2006) Integrating design and retail in the clothing value chain: An empirical study of the organisational design. International Journal of Operations and Product Management 26(3/4): 412-428.

Ahmed S and Ashraf RM (2018) The workshop as a qualitative research approach: Lessons learnt from a "critical thinking writing workshop". The Turkish Online Journal of Design, Art and Communication September Special Edition: 1504-1510.
Andrews D (2015) The circular economy, design thinking and education for sustainability. Local Economy 30(3): 305-315.

Brown L (1997) Competitive Marketing. Melbourne: Nelson.

Chivaka R (2007) Strategic cost management: Value chain analysis approach. Accountancy $S A, 24-27$ August.

Collins Online Dictionary (2020) Available at: www.collinsdictionary.com/dictionary/ english/workshop (accessed 9 March 2020).

Cornwall A and Jewkes R (1995) What is participatory research? Social Science \& Medicine 4(12): 1667-1676.

DEA (Department of Environmental Affairs) (2012) South Africa: State of waste report. Available at: www.dea.gov.za (accessed 13 November 2019).

DEA (Department of Environmental Affairs) (2017) South Africa: State of waste report. Available at: www.dea.gov.za (accessed 13 November 2019).

DEA (Department of Environmental Affairs) (2018) South Africa: State of waste report. Available at: www.dea.gov.za (accessed 13 November 2019).

Du Toit M, De Witte H, Rothmann S, et al. (2018) Contextual factors and the experience of unemployment: A review of qualitative studies. South African Journal of Economic and Management Sciences 21(1): a2083.

Erlandson DA, Harris EL, Skipper B, et al. (1993) Doing Naturalistic Inquiry: A Guide to Methods. Newbury Park, CA: Sage Publications.

Godfrey L, Muswema A, Strydom W, et al. (2017) Co-operatives as a developmental mechanism to support job creation and sustainable waste management in South Africa. Sustainability Science 12: 799-812.

Godfrey L and Oelofse S (2017) Historical view of waste management and recycling in South Africa. Resources 6(4): 57.

GreenCape (2017) Waste economy: Market intelligence report 2017. Available at: www. green-cape.co.za/assets/Uploads/GreenCapeWaste-MIR-2017-electronic-FINAL-v2.pdf (accessed 20 November 2019).

GreenCape (2019) Waste: Market intelligence report. Available at: www.greencape.co.za (accessed 13 November 2019). 
Grigore ME (2017) Methods of recycling, properties and applications of recycled thermoplastics polymers. Recycling 2(24): 1-11.

Hellin J and Meijer M (2006) Guidelines of Value Chain Analysis. Rome: Food and Agriculture Organisation (FAO), UN Agriculture Development Economics Division.

Houghton C, Casey D, Shaw D, et al. (2013) Rigour in quantitative case-study research. Nurse Researcher 4: 12-17.

Humphrey J and Navas-Aleman L (2010) Value chains, donor interventions and poverty reduction: A review of donor practice. IDS Research Reports 63: 1-106.

Jaligot R, Wilson DC, Cheeseman CR, et al. (2016) Applying value chain analysis to informal sector recycling: A case study of the Zabaleen. Resources, Conservation and Recycling 114: 80-91.

Jansen JD (2002) Mergers in Higher Education: Lessons Learned in Transitional Contexts. Pretoria: UNISA Press.

Lain S (2017) Show, don't tell: Reading workshop fosters engagement and success. Journal of Literacy Education 5(2): 160-167.

Lincoln YS and Guba EG (1985) Naturalistic Inquiry. London: Sage Publications Inc.

Kaplinsky R and Morris M (2003) Governance matters in value chains. Developing Alternatives 9: 11-18.

Mattes R (2014) South Africa's emerging black middle class: A harbinger of political change. Working paper no. 151. Journal of International Development 27(5): 665-692.

Merriam SB (1998) Qualitative Research and Case Study Applications in Education. 2nd ed. San Francisco, CA: Jossey-Bass Education Series.

Milios L, Christensen LH, McKinnon D, et al. (2018) Plastic recycling in the Nordics: A value chain market analysis. Waste Management 76: 180-189.

Ørngreen R and Levinsen K (2017) Workshops as a research methodology. The Electronic Journal of e-Learning 15(1): 70-81.

Owen E (2006) Conversational space and participant shame in interviewing. Qualitative Inquiry 12(6): 1160-1179.

Plastics SA (2017) The South African Plastics Recycling Industry - Progress. Waste Management Colloquium. Good Hope
Chamber, Good Hope Building, Parliament. Available at: http://pmg-assets.s3-website-euwest-1.amazonaws.com/ 170314Plastics_SA_Colloquium.pdf (accessed 3 February 2020).

Pandey SC and Patnaik S (2003) Establishing reliability and validity in qualitative inquiry: A critical examination. Jharkhand Journal of Development and Management Studies 12(1): 5743-5753.

PETCO (2020) Who we are. Available at: www. petco.co.za/who-we-are/ (accessed 2 March 2020).

Porter M (1985) Competitive Advantage. New York: The Free Press.

RSA (Republic of South Africa) (1989) Environment Conservation Act 73 of 1989. Government Gazette No. 11927, Notice No. 1188. 1989. Available at: www.environment. gov.za/sites/default/files/legislations/environ ment_conservation_act73of1989.pdf (accessed 14 April 2019).

RSA (Republic of South Africa) (1994) Reconstruction and Development Programme: Parliament of South Africa White Paper on Construction and Development. Government Gazette, Cape Town, 15 November.

RSA (Republic of South Africa) (2008) National Environmental Management: Waste Act 59 of 2008. Government Gazette No. 32000, Notice No. 278. 2009. Available at: www.envi ronment.gov.za/sites/default/files/ legislations/nema_amendment_act59.pdf (accessed 14 June 2019).

RSA (Republic of South Africa) (2013) National Development Plan (NDP) 2030. Available at: www.gov.za/issues/national-developmentplan-2030 (accessed 17 September 2019).

RSA (Republic of South Africa) (2014) National Environmental Management: Waste Amendment Act 26 of 2014. Government Gazette No. 36784, Notice No. 449. 2014. Available at: www.environment. gov.za/ sites/default/files/legislations/nemwa_actno26of2014.pdf (accessed 2 August 2019).

Scheinberg A (2011) Value added: Models of sustainable recycling in the modernisation of waste management systems. $\mathrm{PhD}$ Thesis, Wageningen University, the Netherlands. Available at: www.edepot.wur.nl/179408 (accessed 1 September 2019). 
Scheinberg A (2012) Informal sector integration and high performance recycling: Evidence from 20 cities. Women in Informal Employment Globalisation and Organising (WIEGO). Working Paper (Urban Policies) No. 23. Available at: www.wiego.org/sites/ wiego.org/files/pubilcagtions/files/Scheinberg. WIEGO.WP23.pdf (accessed 1 September 2019).

Scheinberg A and Simpson M (2015) A tale of five cities: Using recycling frameworks to analyse inclusive recycling performance. Waste Management \& Research 33: 975-985.

Shenton AK (2004) Strategies for ensuring trustworthiness in qualitative research projects. Education for Information 22(2): 63-75.

Spagnoletti C, Spencer A, Bonnema R, et al. (2013) Workshop preparation and presentation: A valuable form of scholarship for the clinician educator. Journal of Graduate Medical Education 5(1): 155-156.

Spradley J (1979) The Ethnographic Interview. New York: Holt, Rinehart and Winston.

Stabell CB and Fjeldstad ØD (1998) Configuring value for competitive advantage: On chains, shops and networks. Strategic Management Journal 19: 413-437.

Stats SA (Statistics South Africa) (1998) Unemployment and employment in South Africa 1994-1997. Available at: www. statssa.gov.za/publications/

EmployUnemploy/EmployUnemploy 1997. pdf (accessed 14 January 2020).

Stats SA (Statistics South Africa) (2016) Community survey. Available at: www. statssa.gov.za/?page_id $=6283$ (accessed 17 November 2019).

Stats SA (Statistics South Africa) (2018) Statistical release - Mid-year population estimates 2018. Available at: www.statssa.gov.za/ publication s/P0302/P03022018.pdf (accessed 13 November 2019).
Stats SA (Statistics South Africa) (2019) Quarterly labour force survey, 3rd quarter 2019. Available at: www.statssa.gov.za (accessed 18 November 2019).

Steuer B, Ramusch R, Part F, et al. (2017) Analysis of the value chain network structure of informal waste recycling in Beijing, China. Resources, Conservation and Recycling 117: 137-150.

Taylor V and Triegaardt J (2018) The Political Economy of Social Welfare Policy in Africa: Transforming Policy Through Practice. Cape Town: Oxford University Press.

Velis CA, Wilson DC, Rocca O, et al. (2012) An analytical framework and tool ('InteRa') for integrating the informal recycling sector in waste and resource management systems in developing countries. Waste Management \& Research 30(Suppl. 9): 43-66.

Viljoen J, Blaauw D and Schenck C (2019) The opportunities and value adding activities of buy-back centres in South African recycling industry: A value chain analysis. Local Economy34: 294-315.

Wallendorf M and Belk RW (1989) Assessing trustworthiness in naturalistic consumer research. In: Hirschman EC (ed) $S V$ Interpretive Consumer Research. Provo, UT: Association for Consumer Research, pp. 69-84.

Wilson DC, Velis CA and Rodic L (2013) Integrated sustainable waste management in developing countries. Proceedings of the Institution of Civil Engineers - Waste and Resource Management 166(WR2): 52-68.

Zamora EA (2016) Value chain analysis: A brief review. Asian Journal of Innovation and Policy 5(2): 116-128.

Zott C, Amit R and Massa L (2011) The business model: Recent developments and future research. Journal of Management 37(4): 1019-1042. 